\title{
Metastasizing Pleomorphic Adenoma Case Report and Review of the Literature
}

\author{
Rana Alshagroud ${ }^{1}$ Amandip $\mathrm{Kamoh}^{2} \cdot$ Saurin R. Popat ${ }^{3,4}$. \\ Margaret Brandwein-Weber $^{5} \cdot$ Alfredo Aguirre $^{6}$ (i)
}

Received: 3 February 2017 / Accepted: 7 April 2017 / Published online: 25 May 2017

(C) Springer Science+Business Media New York 2017

\begin{abstract}
Pleomorphic adenoma (PA) is by far the most common salivary gland tumor. It is well known that PA can undergo malignant transformation. However, in rare occasions it can metastasize preserving its benign phenotype. Metastasizing pleomorphic adenoma (MPA) constitutes an extremely rare tumor. Here we are reporting an unusual MPA affecting the mandible that was preceded by a submandibular gland pleomorphic adenoma.
\end{abstract}

Keywords Pleomorphic adenoma $\cdot$ Metastasizing pleomorphic adenoma $\cdot$ Intraosseous

Alfredo Aguirre

aguirr@buffalo.edu

1 Advanced Oral and Maxillofacial Pathology Program, Department of Oral Diagnostic Sciences, School of Dental Medicine, University at Buffalo, The State University of New York, Buffalo, NY, USA

2 Department of Oral and Maxillofacial Surgery School of Dental Medicine, University at Buffalo, The State University of New York, Buffalo, NY, USA

3 Department of Otolaryngology, School of Medicine and Biomedical Sciences, University at Buffalo, The State University of New York, Buffalo, NY, USA

4 Erie County Medical Center and Delaware Medical Group, Buffalo, NY, USA

5 Department of Pathology, School of Medicine and Biomedical Sciences, University at Buffalo, The State University of New York, Buffalo, NY, USA

6 Department of Oral Diagnostic Sciences, School of Dental Medicine, University at Buffalo, 355 Squire Hall, Buffalo, NY 14214, USA

\section{Introduction}

Salivary gland neoplasms represent approximately 2.0-6.5\% of all head and neck tumors [1]. Pleomorphic adenoma (PA), also known as benign mixed tumor, is by far the most common salivary gland tumor affecting both adults and children. It accounts for approximately 60-70\% of all salivary gland neoplasms [2-4]. Approximately $80 \%$ of PAs are found in the parotid gland and the remaining $20 \%$ are situated in the submandibular gland and minor salivary glands. The palate is the most common intraoral site followed by the upper lip [5]. Rarely, PAs have been reported in cervical lymph nodes, soft tissues of the neck, upper and lower limbs, axilla, trunk, lung, breast, sellar region, lacrimal glands and sac, ear and mediastinum [6]. Intraosseous PAs are extremely rare with approximately ten cases reported in the gnathic bones [7]. PA can also occurs synchronously or metachronously with other PAs, as well as other salivary tumors [8]. Here, we report an unusual case of what it was initially believed to be a rare example of an intraosseous PA. However, additional clinical information was obtained and revealed that the patient had a submandibular PA excised 9 years earlier. This sequence of events prompted us to speculate on two possibilities: either these tumors represent a metachronous presentation of submandibular and intraosseous PAs or they represent a rare case of metastatic pleomorphic adenoma. We have done an extensive review of the pertinent literature in an effort to address this question.

\section{Case Report}

A 17-year-old Caucasian female presented for extraction of her third molars. A comprehensive evaluation 
revealed an asymptomatic radiolucency in the left parasymphyseal region. The panoramic film showed a welldefined $2.0 \mathrm{~cm}$, unilocular radiolucency extending from the periapical area of tooth \#24 to the mesial area of tooth \#21 (Fig. 1a). Root resorption was observed on tooth \#23. Intraoral palpation revealed a non-tender firm expansion on the buccal aspect of teeth \#22-24. The teeth involved tested vital to electric and thermal probing. Axial and sagittal views, as well as 3D reconstruction of a cone beam computed tomography (CBCT) scan, revealed intact facial and lingual bony plates of the mandible with no evidence of perforation (Fig. 1b, c). Based on the clinical and radiographic findings a differential diagnosis included odontogenic lesions (cyst or tumor), and a benign fibro-osseous lesion (early stage). The third molars were extracted and an incisional biopsy of the osseous lesion was performed.

Macroscopically, the specimen consisted of multiple tan brown fragments of soft tissue, measuring in aggregate of $1.5 \times 1.0 \times 0.6 \mathrm{~cm}$. Microscopic examination revealed the presence of a benign salivary gland tumor composed of a mixture of myoepithelial and epithelial ductal cells within a myxoid mesenchymal background. Adluminal ductal epithelial cells with an intraluminal eosinophilic coagulum, abluminal clear myoepithelial cells and areas of chondroid metaplasia were present (Fig. 2). Vital bone spicules indigenous to the mandible were noted in close proximity to areas of chondroid metaplasia and epithelial tumor cells. In some areas, congeries of plasmacytoid cells with interspersed ductal epithelial

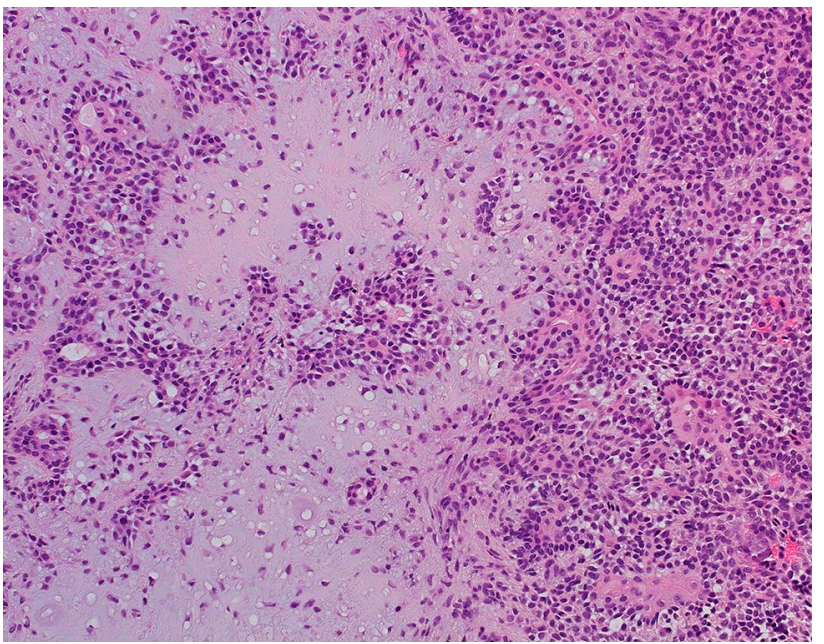

Fig. 2 Biphasic epithelial and myoepithelial cell proliferation forming ductal structures and solid areas with central squamous metaplasia and intervening chondroid tissue (H\&E stained $5 \mu \mathrm{m}$ sections; Original magnification $\times 200$ )

tumor cells were also present (Fig. 3). The final diagnosis was intraosseous pleomorphic adenoma.

Upon further review of the patient's medical history, it was discovered that in 2006 she had undergone resection of a pleomorphic adenoma of the left submandibular gland. Our review of the corresponding tissue sections revealed an encapsulated tumor (Fig. 4). The tumor showed the classic features of a pleomorphic adenoma with a proliferation of epithelial cells and interspersed
Fig. 1 a Panoramic film shows the presence of a circumscribed unilocular radiolucency producing resorption of tooth \# 23. b CBCT axial view demonstrating the extent of bone destruction in the anterior left mandible. c CBCT three-dimensional reconstruction illustrating root resorption of tooth \# 23 with associated large periapical radiolucency. d Panoramic film taken 10 months after surgery demonstrates adequate bone regeneration of the surgical area

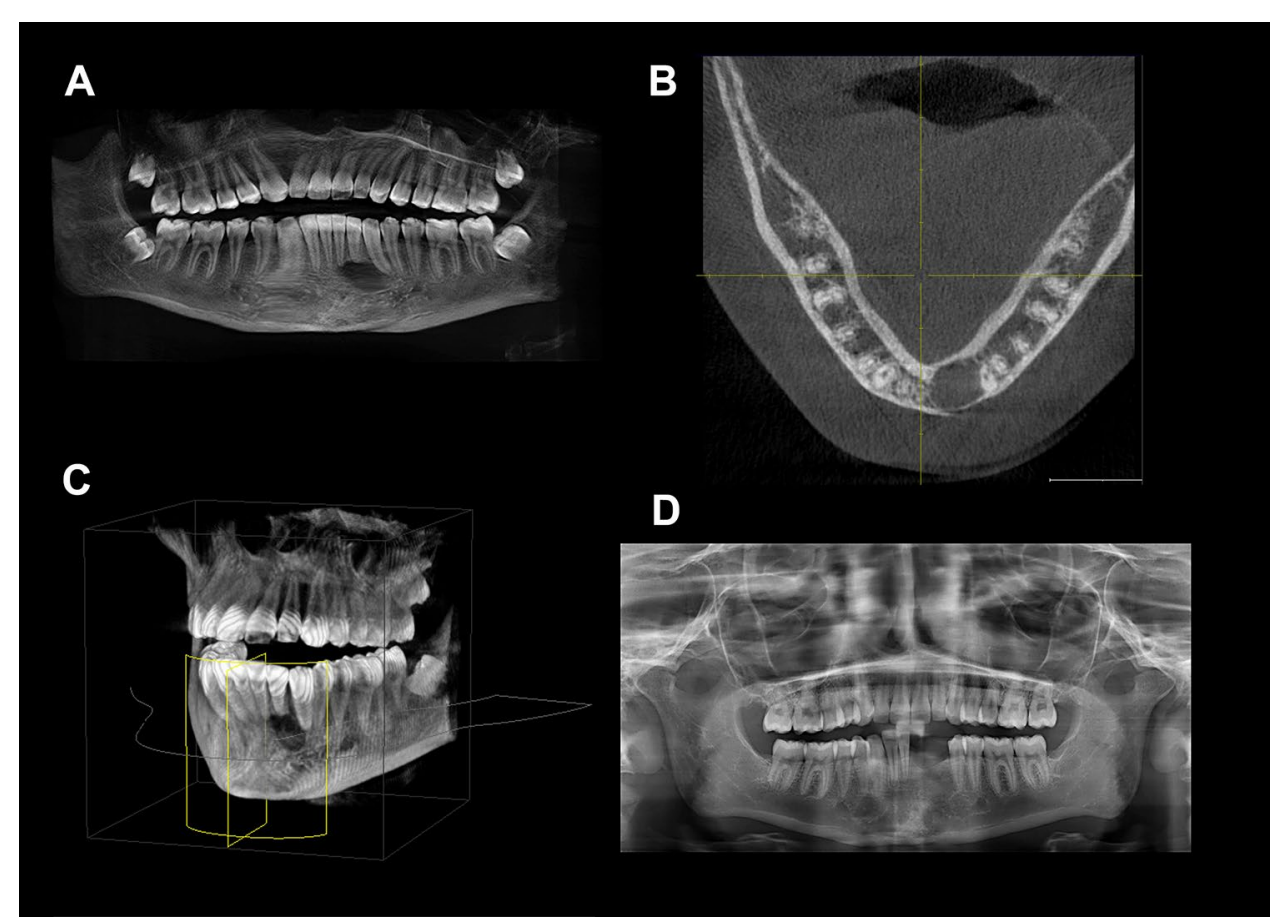




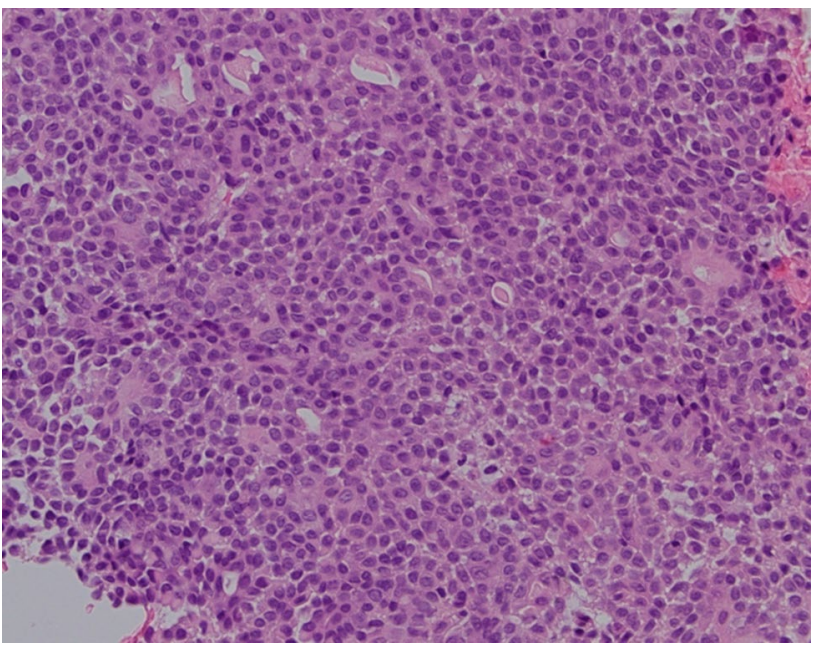

Fig. 3 Sheets of plasmacytoid cells with intervening ductal epithelial structures. Occasional nuclear hyperchromatism and atypia are noted (H\&E stained $5 \mu \mathrm{m}$ sections; Original magnification $\times 400$ )

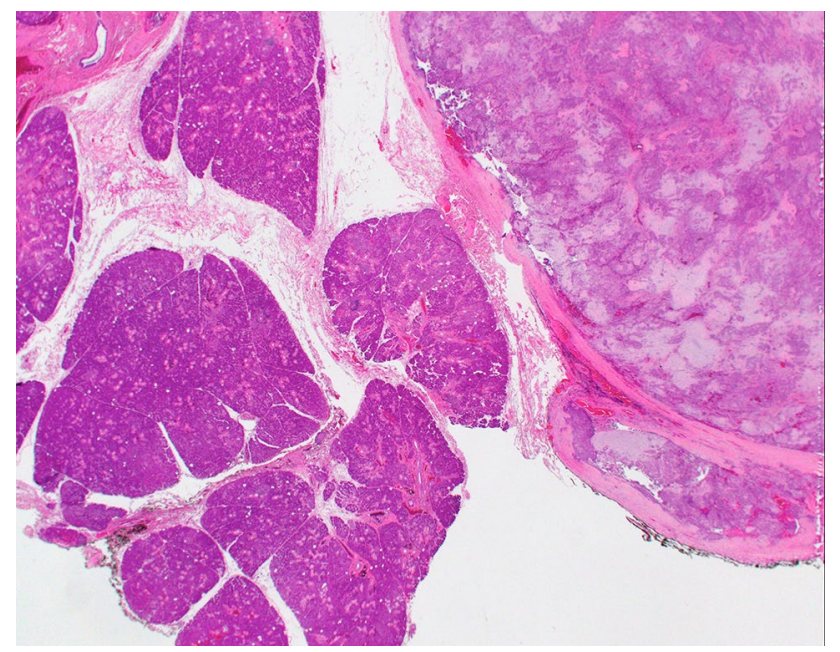

Fig. 4 Low power view of the submandibular neoplasm shows encapsulation of the tumor including a pseudopod. The periphery of the submandibular gland lobules and the tumor are inked and show negative surgical margins (H\&E stained $5 \mu \mathrm{m}$ sections; Original magnification $\times 10$ )

islands of cartilaginous metaplasia (Fig. 5a). There was some mitotic activity but no cytological pleomorphism was present (Fig. 5b). Additionally, it was noted that the tumor was not myxoid predominant. The surgical margins were negative. No local recurrence has been reported since the lesion was excised 9 years earlier. The previous history of a salivary gland tumor of the submandibular gland and the recently diagnosed intraosseous lesion, suggested that this case represented either metachronous pleomorphic adenoma or metastasizing pleomorphic adenoma (MPA).

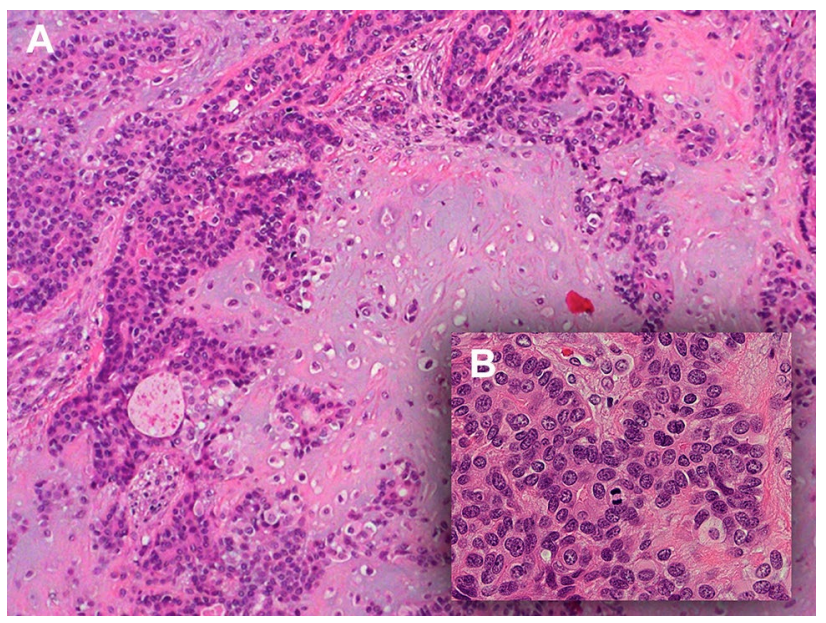

Fig. 5 a Typical microscopic features of the submandibular pleomorphic adenoma showing chondroid metaplasia and a biphasic pattern with ductal epithelial and abluminal myoepithelial cells (H\&E stained $5 \mu \mathrm{m}$ sections; Original magnification $\times 200$ ). b High power view of the submandibular PA showing a normal mitotic figure (H\&E stained $5 \mu \mathrm{m}$ sections; Original magnification $\times 1000$ )

Preoperative CT imaging with and without contrast demonstrated a well-circumscribed lobular $0.9 \times 1.3 \times 1.1 \mathrm{~cm}$ (anterior-posterior, transverse, craniocaudal) non-enhancing lytic soft tissue mass within the left mandibular body. There was erosion of the root of tooth \#23. Scattered lymph nodes of normal size and architecture were seen in the left submandibular space where there was an absence of the submandibular gland.

The patient was brought to the operating room and nasotracheal intubation was performed. Teeth \# 22, 23 and 24 were extracted. A mucosal incision of the alveolar ridge was done and the buccal and lingual alveolar ridge mucosae were liberated, including a portion of the floor of the mouth. The interdental alveolar bone and the inferior aspect of the extraction sockets were osteotomized until the tumor was visualized. The tumor was easily removed using a curette and was then sent off for frozen sections. The frozen sections were consistent with a diagnosis of pleomorphic adenoma. Given that there was limited disease with intact medial, lateral and inferior mandibular cortices, a direct en bloc resection was favored over a segmental osteotomy, which was contraindicated in this young patient with otherwise intact dentition and ability to generate full masticatory/bite forces. At this time, a peripheral ostectomy of the tumor resection cavity was done until no visual evidence of residual disease under loupe magnification $(\times 4.5)$. Bleeding was minimal. The mucosa from the floor of mouth was then elevated, advanced anteriorly and sutured with a 3-0 chromic suture in a running fashion.. The resection specimen was pale tan, soft, measuring $0.6 \mathrm{~cm}$ at its greatest dimension. Histologically, residual foci of typical 
pleomorphic adenoma were seen within fibrous connective tissue.

This patient has been followed now for over 20 months, with serial clinical examinations and two CT scans at 4 months and 10 months after surgery, with no evidence of local or regional recurrence. A panoramic film obtained 6 months after surgery revealed regeneration of bone within the surgical cavity (Fig. 1d). The patient will be followed with increasing time periods between serial CT scans for a proposed 10 years.

\section{Discussion}

Pleomorphic adenoma (PA) is a benign salivary gland neoplasm of epithelial origin that exhibits a variable phenotype $[9,10]$. Most cases of PA arise in major and minor salivary glands [9]. However, intragnathic PAs are uncommon [7]. Although the genesis of intraosseous salivary gland tumors, including PA, remains uncertain, the presence of embryonic and choristomatous salivary tissues in the jaws has been previously reported [11]. More specifically, mucus metaplasia of odontogenic epithelium, aberrant induction of salivary tissue from dental lamina and entrapment of surface glandular tissue within bone during fetal development have been proposed as possible explanations for the existence of central salivary gland neoplasms [11].

In 1979, Batsakis suggested that the criteria to diagnose a central salivary gland neoplasm should include; (1) radiographic evidence of bone destruction with intact cortical plates, (2) no evidence of another salivary gland primary tumor, (3) intact overlying mucosa and, (4) histological confirmation [12]. Although these parameters are currently widely accepted, the requirement of cortical integrity may not be indispensable as perforation may occur in bona fide intragnathic salivary gland neoplasms [13].

Since the publication of the first case of intraosseous gnathic PA (IPA) by Rosenthal in 1927 in the German literature, only few additional cases have been documented [14]. We excluded from our review cases of intraosseous pleomorphic adenomas with malignant features. A comprehensive review of the English language literature from
1960 up to March 2016 revealed only 9 documented cases of IPA. A critical analysis of those reported cases showed that only four of those cases fulfilled the criteria for a primary IPA (Table 1). Five cases lacked clear histological evidence of IPA [15-19]. Interestingly, three of those cases that we rejected have been continuously included in several review articles and have been considered to represent well documented cases of IPA [7, 18, 20-22]. More specifically, the paper by Miller and Winnick did not originally report an IPA, but rather, a "salivary gland inclusion in the anterior mandible." The description of the radiographic, surgical and microscopic findings of this case are strongly suggestive of an anterior Stafne's defect [16]. In the paper by Hoffer and Vogel, the microscopic images and histopathological description are consistent with a diagnosis of central mucoepidermoid carcinoma, rather than IPA [15]. Breitenecker and Wepner's paper illustrated an intraosseous pleomorphic adenoma with malignant transformation that perforated the cortical plates and closely approximated the overlying gingival epithelium [17]. Sadeghi and Darling's publication reported a "cystic pleomorphic adenoma" where there is no convincing photographic evidence documenting the microscopic features of pleomorphic adenoma. Furthermore, the radiographic film presented shows disruption of the crestal bone thus suggesting a soft tissue rather than an intraosseous origin [18]. Finally, Aghaghazvini and Aghaghazvini's paper only showed imaging studies and lacks microscopic proof of a pleomorphic adenoma [19].

Initially, we considered our case to represent a bona fide unusual IPA based on the imaging studies and the microscopic findings of the incisional biopsy. The imaging studies confirmed the presence of intact mandibular cortical plates supporting a central origin of this tumor. Histologically, the neoplasm showed beyond a doubt the classic features of pleomorphic adenoma. However, when additional clinical information became available indicating that the patient had had a submandibular PA excised 9 years prior to the identification and diagnosis of the IPA, the possibility of metastasizing pleomorphic adenoma (MPA) was entertained. When considering MPA, it is important to evaluate the age of the patient, location of the putative metastatic lesion, number of recurrences, time elapsed between
Table 1 Summary of bona fide published cases of primary gnathic intraosseous pleomorphic adenoma fulfilling Batsakis' criteria

\begin{tabular}{llllll}
\hline References & $\begin{array}{l}\text { Number of } \\
\text { cases }\end{array}$ & Site & Age & Sex & Clinical presentation \\
\hline Aver-De-Araujo et al. [22] & 1 & Maxilla & 31 & F & $\begin{array}{c}\text { Swelling and inability } \\
\text { to wear dentures }\end{array}$ \\
Ferretti et al. [21] & 2 & Maxilla & 19 & M (1) & $\begin{array}{c}\text { Swelling and drainage } \\
\text { Ojha et al. [7] }\end{array}$ \\
& 1 & Mandible & 65 & F & $\begin{array}{c}\text { Swelling and interfer- } \\
\text { ence with wearing } \\
\text { dentures }\end{array}$ \\
\hline
\end{tabular}


the primary and metastatic lesions, possibility of iatrogenic spread, the histopathology of both lesions, the possibility of the presence of other metastatic lesions and any chromosomal or molecular similarities between the two lesions.

MPA constitutes an extremely rare group of neoplasms. It is the least common type of malignancy associated with PA, representing only $1 \%$ of all malignant PAs [23, 24]. Previously, MPA was considered an enigmatic entity where its classification as a malignant tumor was debated [24]. Currently, MPA is a well-recognized low-grade malignancy with poorly understood pathogenesis. In the classification published by the World Health Organization (WHO) in 2005, MPA is defined as a "histologically benign pleomorphic adenoma that inexplicably manifests local or distant metastasis" [25]. Surprisingly, the 2017 WHO classification of salivary gland tumors conspicuously eliminated MPA, ignoring a dearth of evidence that has been documented in the literature! [26]. Despite its benign histological features, the neoplasm has the potential to metastasize and be fatal in $22 \%$ of cases $[24,27,28]$. Unfortunately, the distinction between a conventional benign PA and one with the potential to metastasize is only evident after metastases have been discovered [1].

MPA was first reported by Foote and Frazell in 1953 [29]. Subsequently, more cases of MPA have been reported and 83 cases have been documented in the literature [30-32]. Eighty-one of those cases were addressed in the latest systematic review done by Knight and Ratnasingham in 2015 [30]. The results of their study were similar to Nouraei et al. in 2006. Knight et al. reported the mean age at diagnosis of the primary PA at 34.3 years with a range of 9-73 years. The mean age at diagnosis of MPA was 49.5 years with a range of 11-83 years. The mean time interval between PA and MPA was reported to be 14.9 years ranging from a few months to 51 years. A slight female predilection was documented. The parotid gland was the most common primary site for the initial PA $(74.1 \%)$, followed by the submandibular gland (14.8\%). Bone was the most common site for the metastasis followed by lungs and then lymph nodes.

The age of our patient at the time of diagnosis and treatment of her submandibular gland PA ( 8 years-old) is well below the known mean age for conventional salivary PA. Knight and Ratnasingham hypothesized that a diagnosis of PA in a young individual may represent a risk factor for MPA. Their data showed that most patients who developed MPA had had a PA diagnosed at an age younger than expected [30]. Interestingly, the youngest individuals diagnosed with PA had the highest probability of later developing intracranial metastases [24, 33].

A strong association has been documented between a number of local recurrences and the potential ability of PA to metastasize [34]. Almost $73 \%$ of the reported cases of MPA had a history of local recurrence with $37 \%$ of them demonstrating multiple relapses [30]. In our case, there was no history of local recurrence and our patient developed the intraosseous mandibular lesion 9 years later. In a MPA systematic review performed by Knight (2015), 22 cases out of 81 (24.2\%) had no history of previous local recurrence. Most of these cases had history of primary PA in the parotid gland and only five originated from submandibular glands (Table 2) [30, 35-38]. Strikingly, out of the total 83 cases reported in the literature, only one metastasized to the mandible [30-32]. In 1986, Drinkard et al., reported a case

Table 2 Summary of primary submandibular PAs (no history of local recurrences) with subsequent metastasis

\begin{tabular}{|c|c|c|c|c|c|c|}
\hline Reference & Sex & $\begin{array}{l}\text { Age at time of PA diag- } \\
\text { nosis (site of primary) }\end{array}$ & $\begin{array}{l}\text { Age at time of MPA } \\
\text { diagnosis (site of MPA) }\end{array}$ & $\begin{array}{l}\text { Interval } \\
\text { (years) }\end{array}$ & Outcome & $\begin{array}{l}\text { Survival after MPA } \\
\text { diagnosis (months) }\end{array}$ \\
\hline Wajed et al. [35] & $\mathrm{F}$ & $\begin{array}{l}38 \\
\text { (Submandibular gland) }\end{array}$ & $\begin{array}{l}56 \\
\text { (T9 pedicle and spinal } \\
\quad \text { cord compression) }\end{array}$ & 18 & NR & NR \\
\hline Hyun-Hee Ye et al. [36] & $\mathrm{F}$ & $\begin{array}{l}28 \\
\text { (Left submandibular } \\
\text { gland) }\end{array}$ & $\begin{array}{l}68 \\
\text { (Multiple skin, scalp, } \\
\text { frontal lobe, lungs and } \\
\text { vertebrae) }\end{array}$ & 40 & $\begin{array}{l}\text { Submandibular recur- } \\
\text { rence } \\
\text { Persistence and enlarge- } \\
\text { ment of lung tumors at } \\
1 \text { year }\end{array}$ & NR \\
\hline Yamaguchia et al. [37] & $\mathrm{F}$ & $\begin{array}{l}33 \\
\text { (Right submandibular } \\
\text { gland) }\end{array}$ & $\begin{array}{l}40 \\
\text { (Lung \& sternum) }\end{array}$ & 7 & $\begin{array}{l}\text { Lung \& sternum recur- } \\
\text { rence at } 2 \text { years }\end{array}$ & 24 \\
\hline $\begin{array}{l}\text { Larbcharoensub et al. } \\
\text { [38] }\end{array}$ & $\mathrm{F}$ & $\begin{array}{l}36 \\
\text { (Right submandibular } \\
\text { gland) }\end{array}$ & $\begin{array}{l}45 \\
\text { (Multiple cervical lymph } \\
\text { nodes) }\end{array}$ & 9 & Disease free at 6 months & 6 \\
\hline Knight et al. [30] & M & $\begin{array}{l}62 \\
\text { (Submandibular) }\end{array}$ & $\begin{array}{l}68 \\
(\mathrm{~T} 12 \text { vertebrae) }\end{array}$ & 6 & NR & NR \\
\hline
\end{tabular}

$N R$ not reported 
of benign mixed tumor of the mandible occurring 17 years after the diagnosis of a primary PA in the parotid gland. They were hesitant to consider the mandibular lesion as metastasis from the primary parotid tumor, and preferred the possibility of it being an independent lesion arising from ectopic intraosseous salivary gland tissue [39].

Because most cases of MPA have occurred after surgical treatment of either a primary or a recurrent lesion, it has been postulated that surgical manipulation may allow tumor cells to gain lymphatic or venous access promoting the hematogenous spread of a cytologically benign tumor [37].

Currently, there are no well-established microscopic parameters that may predict metastatic potential for PA. Flow cytometry analyses have revealed aneuploidy in primary PA and/or MPA in two cases reported by Wenig et al. [24]. Karyotypic chromosomal analysis and FISH (fluorescence in situ hybridization) with biotinylated centromere specific probes (chromosomes 1, 3 and whole chromosomes 21 and 22 painting probes) were used in one MPA reported by Jin et al. Numerous translocations, including unbalanced rearrangement of chromosomes that differ from the characteristic cytogenetic findings in non-metastasizing PA were detected [40]. Extensive cytogenetic studies have shown genetic alteration of PLAG1 and HMGA2 genes, including gene rearrangement and amplifications, in PA [41]. In one case of MPA, Alkiba et al., compared immunohistochemical expression of PLAG1 with rearrangement of PLAG1 by RT-PCR in both the primary PA and MPA. They found that both the primary PA and MPA were positive for PLAG1 protein but neither tumor harbored the PLAG1 fusion gene [42].

The mainstay of treatment for PA is complete surgical excision with clear margins. More specifically, for submandibular PA, the surgical treatment dictates total removal of the involved gland [30]. Local enucleation may result in incomplete removal of the tumor and leads to local recurrences and the potential of distant metastases [27]. The foundational treatment for MPA is surgical resection [30] with radiotherapy or chemotherapy playing an ancillary role that is usually minimally effective in controlling the disease progression [6]. The development of distant and/or multiple metastasis(es) within 10 years of the initial diagnosis of a PA carries a poor prognosis. MPA carries a mortality rate of $40 \%[27,30]$.

In conclusion, we report an unusual case of intragnathic (mandibular) PA, which was preceded 9 years earlier by a PA of the submandibular gland. This sequence of events, and the patient's young age raise questions regarding the relationship of these two tumors. Because the initial submandibular PA was surgically excised with adequate negative margins, it is thus unlikely that the intragnathic PA resulted from local extension as the cortical mandibular plate was intact during the 9 years interval with no evidence of soft tissue growth in the submandibular area. While the possibility of an independent, metachronous, intraosseous PA cannot be definitively excluded, our literature review, patient demographics, clinical presentation, and microscopic findings favor the diagnosis of MPA to the mandible. Close follow-up of this patient may provide additional insight into the biological behavior of this rare condition.

\section{Compliance with Ethical Standards}

Conflict of interest The authors declare no conflict of interest.

Research Involving Human and Animal Participants This article does not contain any studies with human participants.

\section{References}

1. Ellis GL, Auclair PL. Tumors of the Salivary Glands. AFIP Atlas of Tumor Pathology. Series 4. Washington: ARP PRESS; 2008. P. 27,372.

2. Eveson JW, Cawson RA. Salivary gland tumours. A review of 2410 cases with particular reference to histological types, site, age and sex distribution. J Pathol. 1985;146(1):51-8. doi:10.1002/path.1711460106.

3. Guzzo M, Ferrari A, Marcon I, Collini P, Gandola L, Pizzi N, et al. Salivary gland neoplasms in children: the experience of the Istituto Nazionale Tumori of Milan. Pediatr Blood Cancer. 2006;47(6):806-10. doi:10.1002/pbc.20637.

4. Spiro RH. Salivary neoplasms: overview of a 35-year experience with 2,807 patients. Head Neck Surg. 1986;8(3):177-84.

5. Kuo YL, Tu TY, Chang CF, Li WY, Chang SY, Shiao AS, et al. Extra-major salivary gland pleomorphic adenoma of the head and neck: a 10-year experience and review of the literature. Eur Arch Otorhinolaryngol. 2011;268(7):1035-40. doi:10.1007/ s00405-010-1437-2.

6. Gnepp DR, Henley JD, Simpson RHW and Eveson J. Pleomorphic adenoma (Benign mixed tumor). In: Gnepp DR editor. Diagnostic Surgical Pathology of the Head and Neck, 2nd edn. Philadelphia: Saunders (Elseviere); 2009. p. 438-449.

7. Ojha J, Bhattacharyya I, Islam MN, Manhart S, Cohen DM. Intraosseous pleomorphic adenoma of the mandible: report of a case and review of the literature. Oral Surg Oral Med Oral Pathol Oral Radiol Endod. 2007;104(2):e21-e6. doi:10.1016/j. tripleo.2006.08.013.

8. Silva SJ, Costa Junior GT, Brant Filho AC, Faria PR, Loyola AM. Metachronous bilateral pleomorphic adenoma of the parotid gland. Oral Surg Oral Med Oral Pathol Oral Radiol Endod. 2006;101(3):333-8. doi:10.1016/j.tripleo.2005.07.025.

9. Friedrich RE, Li L, Knop J, Giese M, Schmelzle R. Pleomorphic adenoma of the salivary glands: analysis of 94 patients. Anticancer Res. 2005;25(3A):1703-5.

10. Zarbo RJ. Salivary gland neoplasia: a review for the practicing pathologist. Mod Pathol. 2002;15(3):298-323. doi:10.1038/ modpathol.3880525.

11. Bouquot JE, Gnepp DR, Dardick I, Hietanen JH. Intraosseous salivary tissue: jawbone examples of choristomas, hamartomas, embryonic rests, and inflammatory entrapment: another histogenetic source for intraosseous adenocarcinoma. Oral Surg Oral Med Oral Pathol Oral Radiol Endod. 2000;90(2):205-17. 
12. Batsakis JG. Tumors of the head and neck: clinical and pathological considerations. 2nd ed. Baltimore. Williams \& Wilkins; 1979. p. 97.

13. Tapia JL, Aguirre A, Garvey M, Zeid M. Mandibular unilocular radiolucency with ill-defined borders. Oral Surg Oral Med Oral Pathol Oral Radiol Endod. 2004;97(3):301-6. doi:10.1016/ S1079210403006796.

14. Rosenthal W. Beitrag zur vViederherstellungschirurgie nach kieferresektion und Nekrose. Arch Klin Chir. 1927;141:248.

15. Hoffer O, Vogel G. Mixed tumor of the salivary glands of the mandible. Report of a case. Oral Surg Oral Med Oral Pathol. 1960;13:519-22.

16. Miller AS, Winnick M. Salivary gland inclusion in the anterior mandible. Report of a case with a review of the literature on aberrant salivary gland tissue and neoplasms. Oral Surg Oral Med Oral Pathol. 1971;31(6):790-7.

17. Breitenecker G, Wepner F. A pleomorphic adenoma (so-called mixed tumor) in the wall of a dentigerous cyst. Oral Surg Oral Med Oral Pathol. 1973;36(1):63-71.

18. Sadeghi EM, Darling JE. Cystic pleomorphic adenoma of the mandible. Int J Oral Maxillofac Surg. 1994;23(2):93-5.

19. Aghaghazvini L, Aghaghazvini S. Intraosseous pleomorphic adenoma of the mandible. Iran. J Radiol. 2015;12(1):e6921. doi:10.5812/iranjradiol.6921.

20. Brookstone MS, Huvos AG. Central salivary gland tumors of the maxilla and mandible: a clinicopathologic study of 11 cases with an analysis of the literature. J Oral Maxillofac Surg. 1992;50(3):229-36.

21. Ferretti C, Coleman H, Altini M, Meer S. Intraosseous myoepithelial neoplasms of the maxilla: diagnostic and therapeutic considerations in 5 South African patients. J Oral Maxillofac Surg. 2003;61(3):379-86. doi:10.1053/joms.2003.50075.

22. Aver-De-Araujo LM, Chaves-Tarquinio SB, Neuzling-Gomes AP, Etges A. Intraosseous pleomorphic adenoma: case report and review of the literature. Med Oral. 2002;7(3):164-70.

23. Bradley PJ. 'Metastasizing pleomorphic salivary adenoma' should now be considered a low-grade malignancy with a lethal potential. Curr Opin Otolaryngol Head Neck Surg. 2005;13(2):123-6.

24. Wenig BM, Hitchcock CL, Ellis GL, Gnepp DR. Metastasizing mixed tumor of salivary glands. A clinicopathologic and flow cytometric analysis. Am J Surg Pathol. 1992;16(9):845-58.

25. Gnepp DR. Metastasizing pleomorphic adenoma. In: Barnes L, Eveson J, Reichart P, Sidransky D, editors. World Health Oraganization Classification of Tumors: Pathology and Genetics of Head and Neck Tumors. Lyon: IARC Press; 2005. p. 245.

26. El-Naggar AK. WHO classification of tumours of the salivary glands. In: El-Naggar AK, Chan JC, Grandis JR, Takata T, Slootweg P, editors. World Health Organization Classification of Tumors: Pathology and Genetics of Head and Neck Tumors. Lyon: IARC Press; 2017. p. 162.

27. Nouraei SA, Ferguson MS, Clarke PM, Sandison A, Sandhu GS, Michaels L, et al. Metastasizing pleomorphic salivary adenoma. Arch Otolaryngol Head Neck Surg. 2006;132(7):788-93. doi:10.1001/archotol.132.7.788.

28. Batsakis JG. Malignant mixed tumor. Ann Otol Rhinol Laryngol. 1982;91:342-3.
29. Foote FW Jr, Frazell EL. Tumors of the major salivary glands. Cancer. 1953;6(6):1065-133.

30. Knight J, Ratnasingham K. Metastasising pleomorphic adenoma: systematic review. Int J Surg. 2015;19:137-45. doi:10.1016/j. ijsu.2015.04.084.

31. Kotani Y, Motoyama Y, Nakai T, Nakase H. Metastasizing pleomorphic adenoma in cavernous sinus: letter to the editor. Acta Neurochir. 2016;158(4):647-8. doi:10.1007/s00701-016-2751-2.

32. Young VS, Viktil E, Loberg EM, Enden T. Benign metastasizing pleomorphic adenoma in liver mimicking synchronic metastatic disease from colorectal cancer: a case report with emphasis on imaging findings. Acta Radiol Open. 2015;4(8):1-5. doi:10.1177/2058460115594199.

33. Tarsitano A, Foschini MP, Farneti P, Pasquini E, Marchetti C. Metastasizing "benign" pleomorphic salivary adenoma: a dramatic case-report and literature review. J Craniomaxillofac Surg. 2014;42(8):1562-5. doi:10.1016/j.jcms.2014.01.014.

34. Reiland MD, Koutlas IG, Gopalakrishnan R, Pearson AG, Basi DL. Metastasizing pleomorphic adenoma presents intraorally: a case report and review of the literature. J Oral Maxillofac Surg. 2012;70(10):531-40. doi:10.1016/j.joms.2012.06.185.

35. Wajed MA, Cardoe N, Gleave JR. Spinal cord compression due to metastasis from a mixed salivary gland tumour. Clin Oncol. 1978;4(3):295-8.

36. Hyun-Hee Y, Cho C-W, Jeon M-Y, Kim D-J. Craniospinal metastasis from a metastasizing mixed tumor of salivary gland: unusual presentation. J Korean Neurosurg Soc. 2007;41:186-9.

37. Yamaguchi T, Ashizawa K, Nagaoki K, Abiru H, Uetani M, Tagawa T, Nagayasu T, Hayashi T. Metastasizing pleomorphic adenoma of the submandibular gland with metastasis to the lung and sternum: CT and MR imaging findings. Eur J Radiol Extra. 2009;72:69-72.

38. Larbcharoensub N, Cert PK, Tungkeeratichai J, Prakunhungsit S, Narkwong L, Leopairut J. Expression of hormonal receptor in patients with metastasizing pleomorphic adenoma of the major salivary gland; a clinicopathological report of three cases. J Med Assoc Thai. 2009;92(9):1250-5.

39. Drinkard DW, Schow CE Jr. Benign mixed tumor of the mandible 17 years after the occurrence of a similar lesion in the parotid gland. Oral Surg Oral Med Oral Pathol. 1986;62(4):381-4.

40. Jin Y, Jin C, Arheden K, Larsson O, Bauer HF, Mandahl N, et al. Unbalanced chromosomal rearrangements in a metastasizing salivary gland tumor with benign histology. Cancer Genet Cytogenet. 1998;102(1):59-64.

41. Katabi N, Ghossein R, Ho A, Dogan S, Zhang L, Sung YS, et al. Consistent PLAG1 and HMGA2 abnormalities distinguish carcinoma ex-pleomorphic adenoma from its de novo counterparts. Hum Pathol. 2015;46(1):26-33. doi:10.1016/j. humpath.2014.08.017.

42. Akiba J, Harada H, Kawahara A, Todoroki K, Nagata S, Yano H. A case of metastasizing pleomorphic adenoma in the maxillary bone appearing twenty years after initial resection of pleomorphic adenoma of the hard palate. Pathol Int. 2013;63(9):463-8. doi:10.1111/pin.12087. 